Revista Monografias Ambientais

Santa Maria, Santa Maria, Edição Especial Curso de

Especialização em Educação Ambiental. 2015, p. 84-90

REMOA/UFSM Monografias Ambientais

Revista do Centro de Ciências Naturais e Exatas - UFSM

ISSN : 22361308

\title{
Educação Ambiental nas Escolas da Rede Municipal de Três Passos - RS
}

Environmental Education In the Schools of the Municipal Net of Três Passos - RS

\author{
Robson Evaldo Gehlen Bohrer ; Divanilde Guerra²; Eduardo Lorensi de Souza ${ }^{3}$; Greicia Senger ${ }^{4}$; Ijaime \\ Royer $^{5}$
}

\author{
${ }^{1}$ Mestre, Três Passos, UERGS, Três Passos, RS, Brasil; ${ }^{2}$ Doutora, Três Passos, UERGS, Três Passos, RS, Brasil; \\ ${ }^{3}$ Doutor, Três Passos, UERGS, Três Passos, RS, Brasi;;; Bolsista, Três Passos, UERGS, Três Passos, RS, Brasil; \\ ${ }^{5}$ Bolsista, Três Passos, UERGS, Três Passos, RS, Brasil
}

Resumo

A Educação Ambiental surgiu como movimento ecológico causado pelos problemas ambientais, e estas questões tornaramse mais urgentes para a sociedade devido ao esgotamento dos recursos naturais, o que ocasionou um aumento dos conflitos ambientais, tornando-se cada vez mais importante a realização de trabalhos educacionais em favor do Meio Ambiente. Projetos de Educação Ambiental tornam-se importantes no sentido da promoção e da difusão dos benefícios da conscientização ambiental, onde a principal função da Educação Ambiental, envolvendo a temática "Meio Ambiente", é a contribuição para a formação de cidadãos que promovam a preservação ambiental. A escola é um dos segmentos que compõem a sociedade contemporânea e é conclamada a atuar como um espaço de discussão e formação de práticas ambientais, devendo ser incorporada no dia-a-dia. O projeto foi desenvolvido junto a 9 escolas fundamentais. Como resultado do projeto, foram desenvolvidas duas Capacitações de Professores e multiplicadores, formulação de uma apostila de orientações sobre Educação Ambiental, bem como a construção de oficinas de brinquedos de pet, material pedagógico e, também, foram realizadas palestras ambientais com um público total de 1379 alunos do $3^{\circ}$ ao $9^{\circ}$ do Ensino Fundamental e a participação de 52 professores, sendo que, destes, 16 docentes tiveram a capacitação ambiental.

Palavras-chave: Movimento, ccapacitação, recursos, multiplicadores, preservação.

\begin{abstract}
The environmental education appeared as ecological movement caused by the environmental problems and these subjects became more urgent for the society due to the exhaustion of the natural resources what it caused an increase of the environmental conflicts, becoming more and more important the accomplishment of educational works in favor of the environment. Projects of Environmental Education become important in the sense of the promotion and diffusion of the benefits of the environmental understanding, where the principal function of the environmental education involving the thematic " environment " is the contribution for the citizens formation that you/they promote the environmental preservation. The school is one of the segments that composes the contemporary society and it is shouted to act as a discussion space and formation of environmental practices, should be incorporate in the day by day. The project was developed 9 fundamental schools. As a result of the project, it was developed two Trainings of Teachers and multipliers, formulation of a study aid of orientations about environmental education, as well as, the construction of workshops of pet toys, pedagogic material and they also form accomplished environmental lectures with a public total of 1379 students of the $3^{\circ}$ to the $9^{\circ}$ of the fundamental teaching and the 52 teachers' participation, belonging to these 16 teachers had the environmental training
\end{abstract}

Keywords: Movement, training, resources, multipliers, preservation. 


\section{Introdução}

A educação ambiental teve seu início nos anos sessenta, onde uma onda de manifestações tomaram conta das ruas de diversos lugares do mundo. Rachel Carson, em sua publicação Primavera Silenciosa, início o alerta para a crise ambiental e que não estávamos apenas diante de pequenos acidentes ambientais solucionáveis com ações locais e sim de desastres ambientais de nível de mundial. Nestes anos, iniciam-se as primeiras manifestações sobre a consciência ambiental expandindo-se durante os anos subsequentes. $\mathrm{O}$ discurso ambiental ganhou status ao ser apropriado também por organizações governamentais em conferências como a das Nações Unidas em 1972, onde após estes debates, as discussões sobre as questões ambientais ampliaramse tanto qualitativamente quanto quantitativamente, pela busca de soluções.

Outra vertente do debate pode situar a crise ambiental dentro de uma crise mais ampla: a crise civilizacional que nos leva a analisar o modelo de desenvolvimento marcado pela racionalidade, tecnologia, crescimento ilimitado, produção, consumo, manejo inconsequente dos recursos naturais. É este modelo de sociedade em que a "racionalidade econômica baniu a natureza da esfera da produção, gerando processos de destruição ecológica e degradação ambiental" (LEFF, 2001), em que estamos inseridos e que, dentro de uma visão crítica, precisa ser problematizado e repensado. Neste contexto, nosso país também tratou de produzir pareceres e leis para assegurar a Educação Ambiental nas escolas. Assim, lê-se no artigo 225 da Constituição Federal de 1988:

\footnotetext{
Todos têm direito ao meio ambiente ecologicamente equilibrado, bem de uso comum do povo e essencial à sadia qualidade de vida, impondo-se ao Poder Público e à coletividade o dever de defendê-lo e preservá-lo para as presentes e futuras gerações.

$\S$ Para assegurar a efetividade desse direito, incumbe ao Poder Público:

VI- Promover a educação ambiental em todos os níveis de ensino e a conscientização pública para a preservação do meio ambiente (BRASIL, 1988).
}

A Política Nacional do Meio Ambiente (PNMA), Lei $\mathrm{n}^{\circ}$ 6.938, de 31 de agosto de 1981 tem como princípio a Educação Ambiental em todos os níveis de ensino, inclusive a educação da comunidade, objetivando capacitá-la para participação ativa na defesa do meio ambiente.

Já a Lei N. 9795 de 1999 que dispõe sobre a Política Nacional de Educação Ambiental (PNEA), trata em seu texto os princípios da Educação Ambiental, que deve ser ampla e ter um enfoque humanista e transdisciplinar, sendo este ainda, humanista, holístico, democrático e participativo, com uma concepção do meio ambiente em sua totalidade, considerando a interdependência entre o meio natural, o socioeconômico e o cultural, sob o enfoque da sustentabilidade; (BRASIL, 1999).

A definição da PNEA nós orienta a uma construção de habilidades para a manutenção e conservação do meio ambiente com a inclusão em todos os níveis e modalidades de ensino, para cumprir esta tarefa. Com uma definição ampla para a discussão sobre meio ambiente, muitos autores acreditam que esse conceito tratado de forma restrita à conservação ambiental, exclui a necessidade da inclusão humana junto as questões ambientais (LOUREIRO, 2002).

$\mathrm{O}$ ambiente escolar possui um papel fundamental para a educação ambiental, tornando-se um caminho para a formação e debate acerca do meio ambiente, onde atualmente já é reproduzida a formação de valores e regras universais entre relações sociais mais livres, igualitárias e fraternas. Neste sentido as atividades ambientais escolarizadas, mesmo sendo ínfimas, contribuem para o desenvolvimento e contribuição à causa ambiental. (GUIMARÃES, 2012)

A escola deve também trabalhar a interdisciplinaridade com alunos sobre as temáticas ambientais, pois uma das principais funções da educação ambiental é a formação de cidadãos conscientes (ZUBEN (1998), BRITTO (2000), GUIMARÃES (2005).

A mudança de mentalidade sobre as relações em entre as ações e práticas correlacionadas ao meio ambiente, estão diretamente ligada com à qualidade de vida, ao tipo de convivência que 
mantemos com a natureza, levando a educação ambiental muito além do conservacionismo, tratando-se de uma mudança radical de mentalidade (GADOTTI, 2000).

Diante destas questões, o presente trabalho teve como objetivo a promoção de educação ambiental nas escolas municipais de Três Passos - RS, por meio de pesquisas, palestras, oficinas com cunho ambiental junto à comunidade escolar, tendo como temas principais: Gestão de Resíduos Sólidos; Conservação e Gestão de Recursos Hídricos; Conservação e Manutenção da Biodiversidade; Conservação e Manutenção do Solo.

\section{Metodologia}

O presente trabalho inicialmente propôs um estudo exploratório, buscando junto as Secretarias de Educação e Meio Ambiente da Prefeitura Municipal de Três Passos o levantamento das principais ações já desenvolvidas no âmbito municipal junto à temática deste trabalho, para servir de base para a difusão da educação ambiental na rede municipal de ensino do município. $O$ foco da pesquisa foi junto às escolas da rede municipal de ensino de Três Passos- RS, onde é trabalhado o programa COM-VIDA (Comissão de Meio Ambiente e Qualidade de Vida na Escola), distribuídas entre as zonas urbana e rural do município.

Neste sentido para obter mais informações foram realizadas reuniões com os representantes da Secretarias Municipais de Educação e Meio Ambiente, os coordenadores do COM-VIDA e os proponentes do Projeto de Educação Ambiental, para um melhor aproveitamento das atividades ambientais já trabalhadas e para o desenvolvimento de novas ações.

\section{Resultados e Discussão}

O presente trabalho foi desenvolvido entre os meses de abril a dezembro de 2014, junto a Secretaria Municipal de Educação de Três Passos. Inicialmente foram promovidas reuniões com a participação dos membros deste projeto, da Secretaria da Educação, da Secretaria do Meio Ambiente e da Coordenação de Educação Superior do município, para a busca de informações dos trabalhos já desenvolvidos.

A rede municipal de ensino fundamental do município de Três Passos atualmente conta com 122 professores e 1414 alunos, distribuídos em 9 escolas de ensino fundamental, conforme descrito na Tabela 01:

Tabela 01 - Escolas Municipais de Ensino Fundamental

\begin{tabular}{c|c|c}
\hline ESCOLAS URBANAS & $\begin{array}{c}\mathbf{N}^{\mathbf{o}} \mathbf{d e} \\
\text { Professores }\end{array}$ & $\begin{array}{c}\mathbf{N}^{\mathbf{o}} \text { de } \\
\text { Alunos }\end{array}$ \\
\hline $\begin{array}{c}\text { Escola Municipal de Ensino Fundamental } \\
\text { ILDO MENEGHETTI }\end{array}$ & 27 & 373 \\
\hline $\begin{array}{c}\text { Escola Municipal de Ensino Fundamental } \\
\text { JOÃO PADILHA DO NASCIMENTO }\end{array}$ & 16 & 239 \\
\hline $\begin{array}{c}\text { Escola Municipal de Ensino Fundamental } \\
\text { 25 DE JULHO }\end{array}$ & 21 & 302 \\
\hline $\begin{array}{c}\text { Escola Municipal Integral de Ensino } \\
\text { Fundamental SÃO JOSÉ }\end{array}$ & 13 & 57 \\
\hline $\begin{array}{c}\text { Escola Municipal de Ensino Fundamental } \\
\text { BISPO P.F.SARDINHA }\end{array}$ & 07 & 152 \\
\hline $\begin{array}{c}\text { Escola Municipal de Ensino Fundamental } \\
\text { COROINHA DARONCHI }\end{array}$ & 15 &
\end{tabular}




\begin{tabular}{c|c|c}
$\begin{array}{c}\text { Escola Municipal de Ensino Fundamental } \\
\text { DOM JOAO BECKER }\end{array}$ & 08 & 65 \\
\hline $\begin{array}{c}\text { Escola Municipal de Ensino Fundamental } \\
\text { GUIA LOPES }\end{array}$ & 08 & 67 \\
\hline $\begin{array}{c}\text { Escola Municipal de Ensino Fundamental } \\
\text { WALLY ELISA HARTMANN }\end{array}$ & 07 & 61 \\
\hline Total & 122 & 1414 \\
\hline
\end{tabular}

Fonte, Autores.

Deste total de professores, foram indicados 09 professores para trabalhar junto ao projeto. Este trabalho foi desenvolvido de forma alternada as aulas, onde os alunos participam de aulas regulares durante os períodos manhã e tarde e no turno oposto participam do Com Vida. O trabalho desenvolvido foi definido em reuniões com professores e coordenadores, com base na necessidade de cada escola conforme Tabela 02:

Tabela 02 - Ações desenvolvidas pelas escolas.

\begin{tabular}{|c|c|}
\hline Escola & Trabalho desenvolvido \\
\hline $\begin{array}{l}\text { Escola Municipal de Ensino } \\
\text { Fundamental ILDO } \\
\text { MENEGHETTI }\end{array}$ & $\begin{array}{l}\text { - Separação correta dos resíduos sólidos, visita } \\
\text { na CITEGEM (Consórcio Intermunicipal de Gestão } \\
\text { Multifuncional), visita na Corsan (Companhia } \\
\text { Riograndense de Saneamento), Pequena Central } \\
\text { Hidrelétrica (PCH). }\end{array}$ \\
\hline $\begin{array}{l}\text { Escola Municipal de Ensino } \\
\text { Fundamental JOÃO PADILHA DO } \\
\text { NASCIMENTO }\end{array}$ & $\begin{array}{l}\text { - Separação correta dos resíduos sólidos, visita } \\
\text { na CITEGEM (Consórcio Intermunicipal de Gestão } \\
\text { Multifuncional), visita na Corsan (Companhia } \\
\text { Riograndense de Saneamento), mostra de ciências. }\end{array}$ \\
\hline $\begin{array}{l}\text { Escola Municipal de Ensino } \\
\text { Fundamental } 25 \text { DE JULHO }\end{array}$ & $\begin{array}{l}\text { - Separação correta dos resíduos sólidos, horta } \\
\text { escolar, compostagem, recolhimento de lixo, mostra de } \\
\text { ciências }\end{array}$ \\
\hline $\begin{array}{l}\text { Escola Municipal Integral de } \\
\text { Ensino Fundamental SÃO JOSÉ }\end{array}$ & $\begin{array}{l}\text { - Ajardinamento, oficinas com material } \\
\text { reciclável, separação correta dos resíduos sólidos. }\end{array}$ \\
\hline $\begin{array}{l}\text { Escola Municipal de Ensino } \\
\text { Fundamental BISPO } \\
\text { P.F.SARDINHA } \\
\end{array}$ & $\begin{array}{l}\text { - Compostagem, separação correta dos resíduos } \\
\text { sólidos, recursos hídricos, feira de ciências, visita } \\
\text { Corsan (Companhia Riograndense de Saneamento) }\end{array}$ \\
\hline $\begin{array}{l}\text { Escola Municipal de Ensino } \\
\text { Fundamental COROINHA } \\
\text { DARONCHI }\end{array}$ & $\begin{array}{l}\text { - Recursos hídricos, visita na Corsan } \\
\text { (Companhia Riograndense de Saneamento), separação } \\
\text { correta dos resíduos, visita CITEGEM (Consórcio } \\
\text { Intermunicipal de Gestão Multifuncional), relógio } \\
\text { biológico, mostra ciências. }\end{array}$ \\
\hline $\begin{array}{l}\text { Escola Municipal de Ensino } \\
\text { Fundamental DOM JOAO } \\
\text { BECKER }\end{array}$ & $\begin{array}{l}\text { Horta, separação correta dos resíduos, visita na } \\
\text { CITEGEM (Consórcio Intermunicipal de Gestão } \\
\text { Multifuncional), recursos hídricos, visita na Corsan } \\
\text { (Companhia Riograndense de Saneamento), visitas em } \\
\text { propriedades rurais. }\end{array}$ \\
\hline $\begin{array}{l}\text { Escola Municipal de Ensino } \\
\text { Fundamental GUIA LOPES }\end{array}$ & $\begin{array}{l}\text { Separação correta dos resíduos, visita na } \\
\text { CITEGEM (Consórcio Intermunicipal de Gestão } \\
\text { Multifuncional), recursos hídricos, visita na Corsan } \\
\text { (Companhia Riograndense de Saneamento), Pequena } \\
\text { Central Hidrelétrica (PCH). }\end{array}$ \\
\hline $\begin{array}{l}\text { Escola Municipal de Ensino } \\
\text { Fundamental WALLY ELISA } \\
\text { HARTMANN }\end{array}$ & $\begin{array}{l}\text { Horta escolar, resíduos sólidos (Citegem e } \\
\text { recolhimento de lixo), trilha ecológica, gincana meio } \\
\text { ambiente. }\end{array}$ \\
\hline
\end{tabular}


A partir dos encontros com professores, e coordenadores de educação da rede municipal de ensino, pode propor ações a serem desenvolvidas durante o projeto. A tabela 03 apresenta as ações desenvolvidas em cada escola participante.

Tabela 03 - Ações desenvolvidas pelo projeto

\begin{tabular}{|c|c|}
\hline $\begin{array}{l}\text { ESCOLAS } \\
\text { URBANAS }\end{array}$ & Ações desenvolvidas pelo projeto \\
\hline $\begin{array}{l}\text { Escola Municipal } \\
\text { de Ensino Fundamental } \\
\text { Ildo Meneghetti }\end{array}$ & $\begin{array}{c}\text { - Para os alunos até o } 5^{\circ} \text { ano aplicamos uma dinâmica } \\
\text { fazendo uso de um "Kit" de mini lixeiras, por cores, e um saco } \\
\text { com resíduos diversos, onde que os alunos participaram da } \\
\text { definição do tipo de resíduo e lixeira correta para descarte. Para } \\
\text { alunos do } 6^{\circ} \text { ao } 9^{\circ} \text { ano foram palestras com o tema da composição } \\
\text { gravimétrica resíduos Três Passos. }\end{array}$ \\
\hline $\begin{array}{l}\text { Escola Municipal } \\
\text { de Ensino Fundamental } \\
\text { João Padilha do } \\
\text { Nascimento }\end{array}$ & $\begin{array}{l}\text { - Para os alunos até o } 5^{\circ} \text { ano aplicamos uma dinâmica } \\
\text { fazendo uso de um "Kit" de mini lixeiras, por cores, e um saco } \\
\text { com resíduos diversos, onde que os alunos participaram da } \\
\text { definição do tipo de resíduo e lixeira correta para descarte. Para } \\
\text { alunos do } 6^{\circ} \text { ao } 9^{\circ} \text { ano foram palestras com o tema da composição } \\
\text { gravimétrica resíduos Três Passos. }\end{array}$ \\
\hline $\begin{array}{l}\text { Escola Municipal } \\
\text { de Ensino Fundamental } \\
25 \text { de Julho } \\
\end{array}$ & $\begin{array}{c}\text { - Diagnóstico da situação da composteira da escola, } \\
\text { mensuração e registro das sobras objetivando a construção de } \\
\text { nova composteira. }\end{array}$ \\
\hline $\begin{array}{l}\text { Escola Municipal } \\
\text { Integral de Ensino } \\
\text { Fundamental São José }\end{array}$ & $\begin{array}{l}\text { - Para os alunos até o } 5^{\circ} \text { ano aplicamos uma dinâmica } \\
\text { fazendo uso de um "Kit" de mini lixeiras, por cores, e um saco } \\
\text { com resíduos diversos, onde que os alunos participaram da } \\
\text { definição do tipo de resíduo e lixeira correta para descarte e para } \\
\text { alunos do } 6^{\circ} \text { ao } 9^{\circ} \text { ano palestras sobre aproveitamento de } \\
\text { materiais para construção de instrumentos musicais. }\end{array}$ \\
\hline $\begin{array}{r}\text { Escola Municipal } \\
\text { de Ensino Fundamental } \\
\text { BISPO P.F.SARDINHA } \\
\end{array}$ & $\begin{array}{c}\text { - Palestra com o tema recursos hídricos abordando a } \\
\text { disponibilidade e importância da preservação da água e sobre } \\
\text { PCH (Pequena Central Hidrelétrica) }\end{array}$ \\
\hline $\begin{array}{l}\text { Escola Municipal } \\
\text { de Ensino Fundamental } \\
\text { COROINHA } \\
\text { DARONCHI } \\
\end{array}$ & $\begin{array}{l}\text { Dinâmicas e oficinas com a confecção de cofrinhos com o } \\
\text { reaproveitamento de garrafas PET. }\end{array}$ \\
\hline $\begin{array}{r}\text { Escola Municipal } \\
\text { de Ensino Fundamental } \\
\text { DOM JOAO BECKER }\end{array}$ & Logística reversa na agricultura e eletrônicos. \\
\hline $\begin{array}{l}\text { Escola Municipal } \\
\text { de Ensino Fundamental } \\
\text { GUIA LOPES }\end{array}$ & Desmatamento e fixação de carbono. \\
\hline $\begin{array}{l}\text { Escola Municipal } \\
\text { de Ensino Fundamental } \\
\text { WALLY ELISA } \\
\text { HARTMANN } \\
\end{array}$ & $\begin{array}{c}\text { Recursos hídricos e palestra sobre projeto "avaliação } \\
\text { ambiental dos principais lajeados e nascentes da sub-bacia do lajeado erval } \\
\text { novo". }\end{array}$ \\
\hline
\end{tabular}

Fonte: Autores.

As ações propostas e desenvolvidas durante o projeto, consideraram as característica de cada escola participante. A principal ação desenvolvida foi com a temática de resíduos sólidos, sendo esta apresentada em 7 escolas, correspondendo a 46,6\% das escolas. Esta temática envolvia desde palestras sobre resíduos sólidos urbanos, resíduos da logística reversa, oficinas 
de pet, e uma dinâmica com lixeiras, apelidada de saco de lixo. Em outras duas escolas foram trabalhados temas como recursos hídricos: palestra sobre projeto "avaliação ambiental dos principais lajeados e nascentes da sub-bacia do lajeado erval novo", e palestra sobre Pequenas centrais hidrelétricas.

Em um trabalho correlacionado, Guimarães (2012) chama a atenção que a maioria dos projetos está concentrada em escolas do ensino fundamental $(74 \%)$ e que há predominância de temas relativos ao plantio de mudas e ao destino de resíduos sólidos.

O projeto ainda proporcionou a formação dos agentes multiplicadores em Educação Ambiental. Esta ação teve como objetivo, a construção e orientação para a formação de pessoal capacitado, para difusão da educação ambiental na rede escolar de ensino de Três Passos - RS, contribuindo para a formação da consciência ambiental e senso crítico. Os agentes multiplicadores foram compostos inicialmente por professores e coordenadores da secretaria de educação e posteriormente alunos da rede Com -Vida.

Alves (2011) deixa evidente a responsabilidade dos professores que devem inovar suas ações pedagógicas promovendo a formação de indivíduos participativos, cabendo a escola básica, universidades, faculdades a função de formar multiplicadores ambientais, desenvolver projetos juntos a comunidade que sensibilize as pessoas para que conscientes promovam ações que viabilizem melhorias.

\section{Conclusão}

Com este trabalho foi possível observar as principais ações desenvolvidas na rede municipal de ensino do município de Três Passos, envolvendo a temática Meio Ambiente, com destaque as questões voltada aos Resíduos Sólidos. Observou-se também a necessidade de trabalhar a temática meio ambiente de forma transdisciplinar nas escolas, em todas as disciplinas e por todos os professores, para a formação de cidadãos mais preocupados com o meio ambiente. Outro aspecto importante observado foi à carência de professores com formação específica da temática meio ambiente, para trabalhar nas escolas, pois atualmente são professores de outras áreas que desenvolvem trabalhos com os alunos. Com o trabalho, pode-se constatar a necessidade de trabalhar a educação ambiental não de forma alternada como é desenvolvida atualmente e sim como disciplina permanente na grade curricular das escolas. Com o encerramento do projeto atingiu-se um público de 1379 alunos e 52 professores levando-se em conta atividades como palestras, dinâmicas de grupo, oficinas e capacitações.

\section{Agradecimentos}

Agradecer a Universidade Estadual do Rio Grande do Sul - Uergs pela disponibilidade e aprovação do projeto de extensão Educação Ambiental na Rede Municipal de Três Passos;

Agradecer a Prefeitura Municipal de Três Passos, em especial a Secretaria de Educação e Meio Ambiente pelo apoio e parceira neste projeto;

Agradecer aos colaboradores, professores, bolsistas e demais pela ajuda e dedicação com o projeto de educação ambiental.

\section{Referências}


ALVES, J. S.; Fonseca, G. S. - Formação de educadores ambientais: Desafios e perspectivas. Revista Geográfica de América Central, 2011, pp. 1-16.

BRASIL. Lei n. ${ }^{\circ} 9795$ - 27 abr. 1999. Dispõe sobre a educação ambiental e institui a política nacional de política ambiental. Diário Oficial da União, Brasília, 28 abr. 1999.

BRASIL. Lei no. 6.938, de 31 de Agosto de 1981. Política Nacional de Meio Ambiente (PNMA). Disponível em: <http://www.planalto.gov.br/ccivil 03/Leis/L6938> Acesso em: jan. 2014.

BRASIL. Constituição da República Federativa do Brasil: promulgada em 5 de outubro de 1988: atualizada até a Emenda Constitucional n ${ }^{\circ} 20$, de 15 de dezembro de dezembro de 1988. Disponível em: <http://www.lei.adv.br/225-88.htm>. Acesso em: jan.2014.

BRITTO, C. Educação e Gestão Ambiental. Salvador: Ministério do Meio Ambiente, 2000.

GADOTTI, Moacir. Pedagogia da Terra. 3ªed. São Paulo: Petrópolis, 2000.

GUIMARÃES, M. A dimensão Ambiental na educação. Campinas-SP: Papirus, 2005.

GUIMARÃES, Z.F.S., Santos, W.L.P., Machado, P.F.L., Baptista, J.A. - Projetos de educação ambiental em escolas: a necessidade da sistematização para superar a informalidade e o improviso. Pesquisa em Educação Ambiental, vol. 7, n. 1 - pp. 67-84, 2012.

LEFF, Henrique. Educação ambiental e desenvolvimento sustentável. In: REIGOTA, Marcos (org). Verde Cotidiano: o meio ambiente em discussão. 2 ed. Rio de Janeiro: DP\&A, 2001. p. 111-129.

LOUREIRO, C. F. B. 2002. Educação Ambiental Crítica: Princípios Teóricos e Metodológicos. 01. ed. Rio de Janeiro: Hotbook. v. 01. p.66.

ZUBEN, F. V. Meio Ambiente, Cidadania e Educação. Departamento de Multímeios. Unicamp. Tetra Pak Ltda. 1998. 